\title{
Vehicular Occupant Star Rating of Highway by iRAP Methodology
}

\author{
[Sandeep K Prusty ${ }^{1}$, Soumya R Nayak ${ }^{2}$, Rashmi R Barik ${ }^{3}$ ]
}

\begin{abstract}
The ever increasing road accidents prompted for road safety assessment in order to assess the accident potential and suggest measures in order to diminish the accident potential. This paved the way for the foundation of Road Assessment Programmers (RAP) which performs systematic analysis of road segments to rectify the safety shortcomings and mitigate.

This study uses the iRAP methodology for star rating and encompasses various road attributes (i.e. lane width, delineation, curvature, grade etc.) which act as an input to iRAP model for generating Star Rating Score (SRS). Star Rating is directly related to risk of accidents. Higher star rating for a road section reduces relative accident risk as compared to lower star rating roads. Also to enhance star rating countermeasures have suggested.

Countermeasures which will enhance the deficient road safety aspects are basic requirements for safe road design (e.g. proper delineation, signage, good riding surface, proper design of intersections etc.). Subsequently, new SRS have been generated which were used for star rating of road section again. It's evident that earlier $75 \%$ of road sections were in 1 or 2 star categories, but after post treatment only $33 \%$ are in 1 or 2 star categories. Hence from revised star rating, we have $67 \%$ of sections in 3 or more star rating which was just $25 \%$ beforehand.
\end{abstract}

Keywords - Road assignment, Vehicular Occupent, Star Rating, iRAP, Traffic Volume, Vehicular Speed

\section{Introduction}

Road accidents inflict huge socio-economic cost for both the individual as well as the concerned country. Massive expansions in the road network, coupled with increased motorization contribute towards increased motorization contribute towards increased numbers of road accidents.

The road accidents deaths and injuries are global phenomena but more sever situation in mixed traffic condition as prevailing on Indian multilane highways.

\footnotetext{
${ }^{1}$ Sandeep K Prusty,

National Institute of Technology, Karnataka India

${ }^{2}$ Soumya Ranjan Nayak,

Indira Gandhi Institute of Technology, Sarang India

${ }^{3}$ Rashmi Ranjan Barik,

Indira Gandhi Institute of Technology, Sarang India
}

India accounted for roughly $10 \%$ of total world's road fatalities in the year 2010 as per the World health Organization [1].

Road users in India are heterogeneous in nature, ranging from pedestrians, animal driven carts, to multi axle commercial vehicles etc. Pedestrians, bicyclists and motorised two-wheeler riders are the Vulnerable Road Users (VRU) constituting 60-80 percent of all traffic fatalities as per the study done by Singh and Vasudevan [2] in India. As per MORTH [3] accidents are bound to occur and even the road with the best safety features and sound proof design can't be ensured to be accident free. However the effect of accident could be minimized. A range of factors contribute towards the occurrences of accident, including faults of driver, pedestrian, cyclist, defects in vehicle, bad weather condition etc.

The increasing number of accidents resulting in fatalities and injuries prompts for the assessment of safety aspects of roads and to suggest mitigative measures. The Star ratings provide a simple and objective measure of the level of safety provided by a road's design. Star Ratings involve an inspection of road infrastructure attributes that are known to have an impact on the likelihood of a crash and its severity.

\section{Study Stretch}

National Highway-48 (NH-48) run between Mangalore to Bangalore, also called as Mangalore -Bangalore Highway is $328 \mathrm{~km}$ long. It is 4-lane divided carriageway for Nelamangala, Bangalore to Hassan section while from Hassan to B.C.Road it's having 2-lane undivided carriageway according to the study based on Feedback Infrastructure Pvt. Ltd. [4].

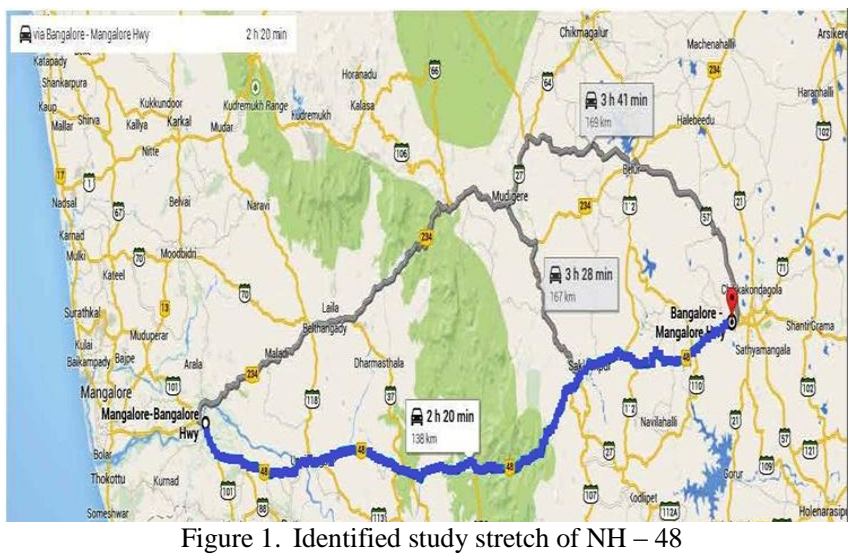

The road stretch selected for this study is from B.C.Road to start of Hassan Bypass section of NH-48 measuring 137.3 
$\mathrm{km}$. The total study section has been divided into 3 segments, i.e. from B.C.Road to Gundiya, Gundiya to Sakleshpura and Sakleshpura to Hassan Bypass because of terrain change. Large number of people has to face tragic and fatal accidents.

TABLE 1. REPORTED ACCIDENTS BETWEEN 01/01/1310/06/14 ON IDENTIFIED STRETCH

\begin{tabular}{|c|c|c|l|}
\hline From & To & $\begin{array}{c}\text { Number } \\
\text { of } \\
\text { accidents }\end{array}$ & Vehicles involved \\
\hline B.C.Road & Gundiya & 11 & Tanker (3), HCV(6),2W(2) \\
\hline Gundiya & Sakleshpura & 21 & Tanker(13),HCV(4),4W(4) \\
\hline Sakleshpura & $\begin{array}{c}\text { Hassan } \\
\text { Bypass }\end{array}$ & 8 & Tanker(1),HCV(5),2W(1),4W(1) \\
\hline
\end{tabular}

HCV- Heavy Commercial vehicle, 4W- Four Wheeler, $2 \mathrm{~W}$ - Two Wheeler

\section{Road Assessment Programme (RAP)}

Road Assessment Programs use a systematic analysis of road segments to address safety shortcomings, mitigate risks and inform drivers about the level of safety on the roads they travel. Their main objective was to reduce deaths and injuries on roads by assessing risk and identifying safety shortcomings that can be addressed by road improvement measures.

iRAP (International Road Assessment Programme) [5] in 2012 has developed four globally-consistent protocols to assess and improve the safety of roads as mentioned below.

- Risk Maps uses thorough crash data to exemplify the actual number of deaths and injuries on a road network.

- Star Ratings provide a simple yet objective measure of the level of safety provided by a road's design.

- Safer Roads Investment Plans rely on around 90 road improvement options to generate affordable and economically viable infrastructure options.

- Performance Tracking enables the use of Star Ratings and Risk Maps to track road safety performance.

\section{A. Star Rating Scores}

A Star Rating Score (SRS) is calculated for each 100 meter segment of road, using the following equation:

Where: $\mathrm{SRS}=\Sigma$ Crash Type Scores

$>$ SRS represents relative risk of death and serious injury for an individual road user

Crash Type Scores =Likelihood x Severity x Operating speed $x$ External flow influence $x$ Median traversability

Star rating will be assigned to each section on the basis of following star band as suggested by iRAP in 2013 [6] is mentioned in Table 2.

TABLE 2.

STAR RATING BANDS

\begin{tabular}{|c|c|}
\hline Star Rating & Vehicular Occupant Star Rating Score \\
\hline 5 & 0 to $<2.5$ \\
\hline 4 & 2.5 to $<5.0$ \\
\hline
\end{tabular}

\begin{tabular}{|c|c|}
\hline 3 & 5.0 to $<12.5$ \\
\hline 2 & 12.5 to $<22.5$ \\
\hline 1 & $22.5+$ \\
\hline
\end{tabular}

\section{B. Operating speed}

It is greater of the posted speed limit or the $85^{\text {th }}$ percentile speed. In model used for iRAP methodology, higher is the speed higher is the risk associated with it. It's evident also because at higher operating speed the likelihood and severity of accidents is manifold as compared to lower speeds.

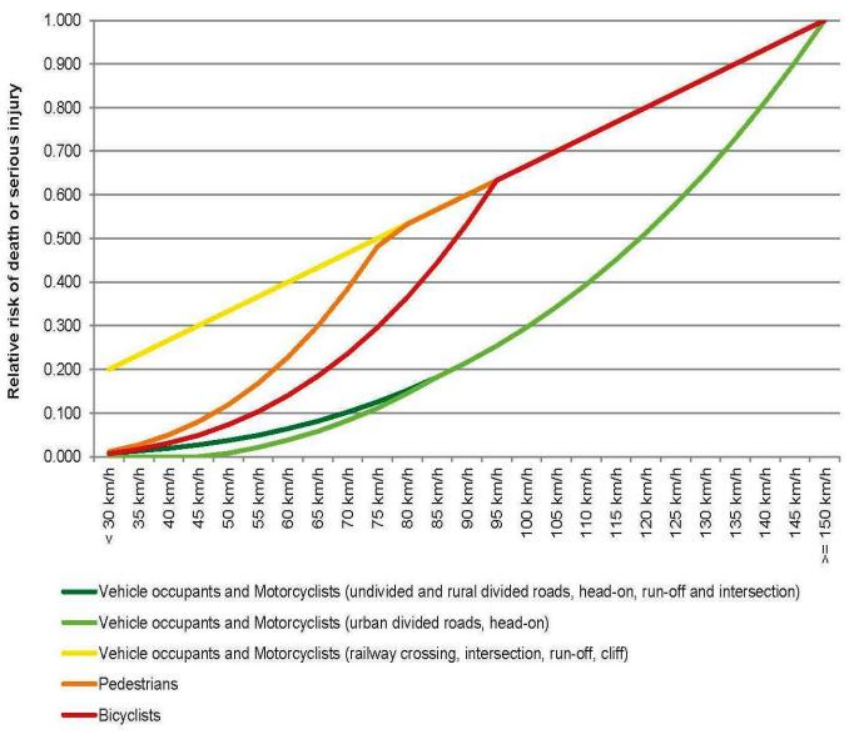

Figure 2. Risk factors associated with operating speed, road user type and crash type

\section{Intersection quality}

It is a measure of intersection design in terms of advance warning, signage and road markings. The risk value associated with it is 1 when adequate or not applicable (NA) and 1.2 when poor.

\section{Intersection external flow influence}

In the absence of traffic volume data on side roads, often it's estimated for assessment. Intersecting traffic influences greatly the star rating score of a particular stretch. Higher will be the chances of accidents at intersections which have been not designed properly yet handle huge traffic. The following figure aid in accounting the risk as a result of side flow. 
Proc. of Fourth International Conference On Advances in Civil, Structural and Mechanical Engineering - ACSM 2016 Copyright (C) Institute of Research Engineers and Doctors, USA .All rights reserved.

ISBN: 978-1-63248-096-5 doi: 10.15224/ 978-1-63248-096-5-41

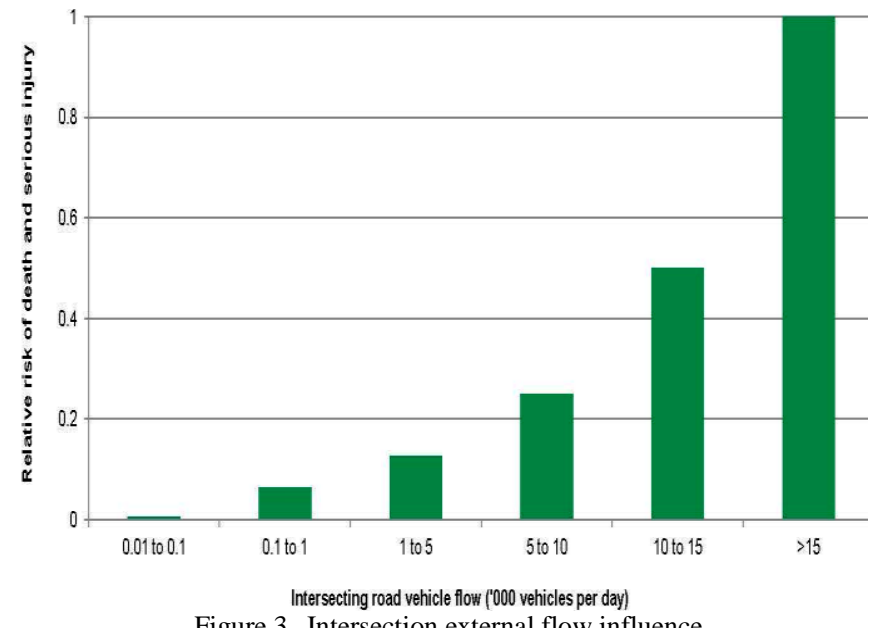

\section{E. Road Attributes}

Various road attributes which are the critical parameters for star rating are mentioned in subsequent sections. Since this study has undertaken only vehicular star rating, only those road attributes will be discussed which are concerned with vehicular star rating. Risk factors, sometimes called crash modification factors (CMF), and are used in the iRAP [7] studied in 2011 with Star Rating methodology to relate road attributes and crash rates.

\section{F. External Flow Influence}

iRAP considers a lane to be saturated only if vehicle flow per day is more than 18000 while it's a unsaturated if vehicle flow is less than 2000 per day. Vehicle flow influences the type of crash a person is likely to be involved in. it has been assumed in iRAP methodology that half of runoff accidents occur on driver side while other on passenger side.

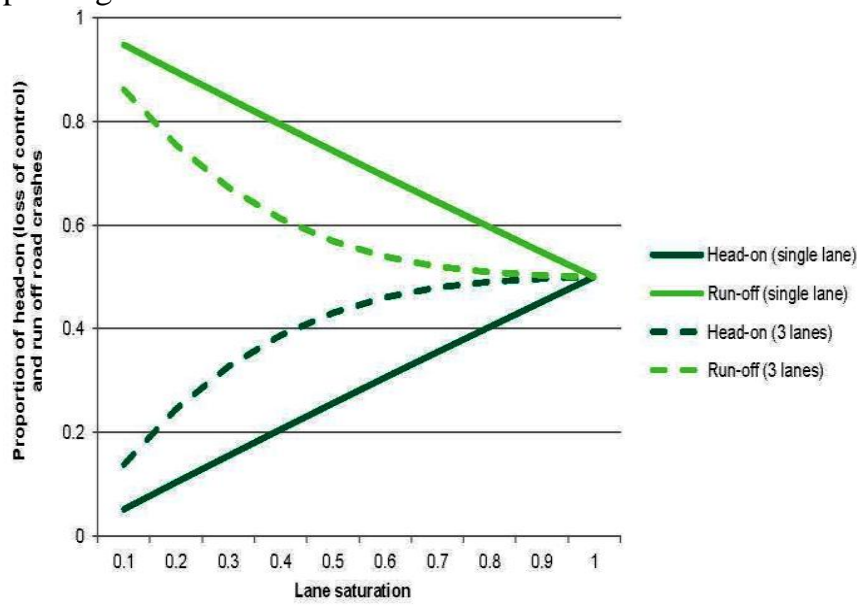

Figure 4. Run-off and Head-on (loss of control) external flow influence factors for undivided roads

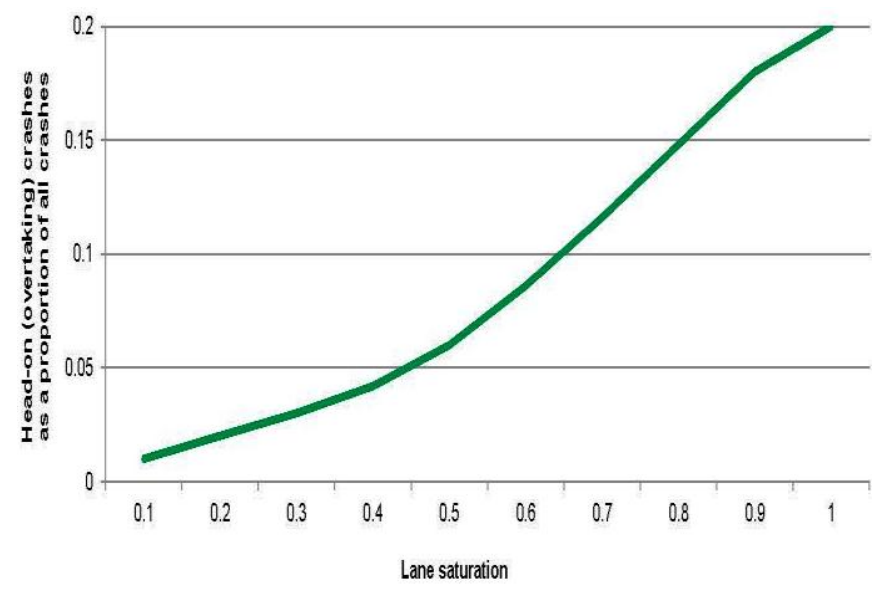

Figure 5. Head-on (overtaking) external flow risk factors

For property access points, where side road flows have not been recorded and are expected to be low, a default value of .01 is adopted.

\section{Methodology}

For this study, B.C.Road to start of Hassan Bypass sections of National Highway-48 was selected. The total length was found to be $137.3 \mathrm{~km}$. This road section passes through two different categories of terrain- plain and mountainous. B.C.Road to Gundiya and Sakleshpura to start of Hassan Bypass comes in plain terrain while Gundiya to Sakleshpura has been placed in mountainous category.

The major reason for the selection of this stretch was the concentrated flow of petro-chemical tankers on this road. Also since this route traverses through the Shiradi Ghat section, it encounters a plethora of terrain changes. This is the shortest route to reach Bangalore from Mangalore. Any accident on this route can be fatal often leading to route closure, thereby causing great discomfort.

\section{A. Data Collection}

Road attributes data were collected during road survey which was conducted on 04 Jan 2014. Road attributes were video recorded while travelling in a test vehicle at a speed 30-40 kmph. Along with video recordings, elevation profile was also recorded with the help an application Global Positioning System (GPS) in order to ascertain the grade. Rest all data's were obtained after analysis of video. Also in some cases, in the absence of accurate and reliable data or due to inability to measure it, appropriate assumptions have been made.

\section{B. Analysis of Data}

The total road length was divided into numerous sections, each measuring $100 \mathrm{~m}$ in length. Henceforth the study stretch of $137.3 \mathrm{~km}$ was split into 1373 sections. Video recordings were analysed to record the road attribute corresponding to these sections. For each section of $100 \mathrm{~m}$, the worst case features of various road attributes were recorded. It meant that if a section was having sharp as well as straight curvature, it was recorded as having sharp curvature. 
Proc. of Fourth International Conference On Advances in Civil, Structural and Mechanical Engineering - ACSM 2016 Copyright (C) Institute of Research Engineers and Doctors, USA .All rights reserved. ISBN: 978-1-63248-096-5 doi: 10.15224/ 978-1-63248-096-5-41

Curvature refers to the change in horizontal alignment of the road. Sharp curves were recorded mostly in plain terrain. Very sharp curves have been recorded exclusively in the Shiradi Ghat section. Very sharp curves were those curves which have posted speed limit of 30-40 kmph for safe manoeuvring. Sharp curves were curves having radius less than $400 \mathrm{~m}$. Figure 6 shows the distribution of curvature in identified stretch.

\section{Curvature}

\section{Straight $\quad$ Moderate $\quad$ Sharp $\quad$ Very sharp}

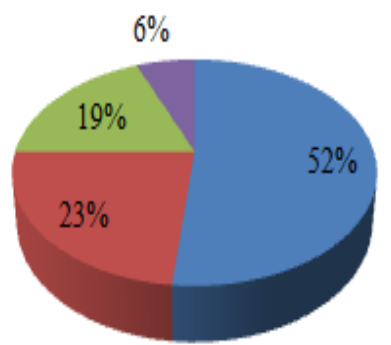

Figure 6. Observed curvature throughout the study stretch

\section{Grade}

On the basis of the output file of Global Positioning System (GPS) application, grade values were determined for each $100 \mathrm{~m}$ section. The Shiradi Ghat section showed great variation in elevation profile.

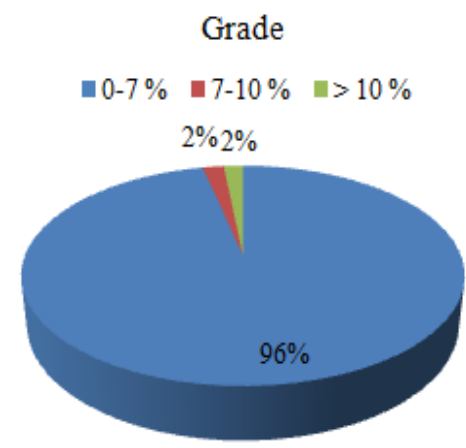

Figure 7. Grade throughout the study stretch

\section{Road Side Severity Distance}

Road side severity distance for both driver side and passenger side were approximately adjudged and recorded. There may be variation in this distance because of error of judgments. The distribution of road side severity distances for both driver and passengers have been recorded in Figure 8 and Figure 9.

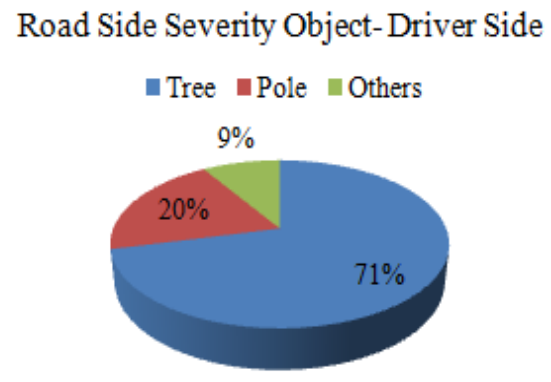

Figure 8. Road Side Severity Distance- Driver Side

Road Side Severity Object-Passenger Side Tree $\square$ Pole $n$ Others

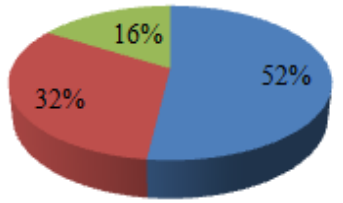

Figure 9. Road Side Severity Distance- Passenger Side

\section{E. Operating Speed}

The operating speed data was collected from the posted speed signage. Elsewhere if not mentioned, operating speed was assumed as $80 \mathrm{kmph}, 50 \mathrm{kmph}$ in rural and urban areas of plain terrain and $40 \mathrm{kmph}$ for Shiradi Ghat section from Gundya to Sakleshpura. Refer to Figure 10 for distribution of operating speed.

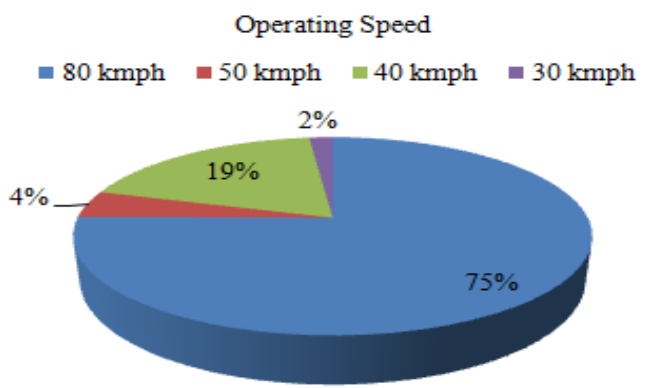

Figure 10. Distribution of operating speed in study stretch

\section{F. Intersection Traffic Volume}

Intersecting Traffic Volume for major intersections was recorded from the road traffic survey database of Karnataka Public Works Department [8]. While for minor intersections involving village roads and other roads were assumed suitably.

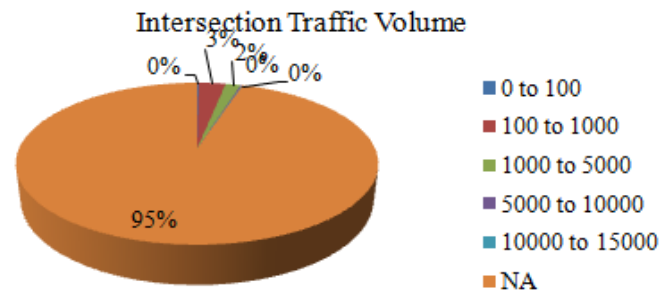

Figure 11. Intersecting Traffic Volume 


\section{G. Assigning Star Ratings to Road sections}

The recorded road attributes were fed into the mathematical model of iRAP methodology, a sample of which has been enclosed in to get Star Rating Score on the basis of which road sections were rated from 1 to 5 stars. Figure 12 shows the distribution of Star Ratings obtained by following the iRAP methodology for 1373 sections.

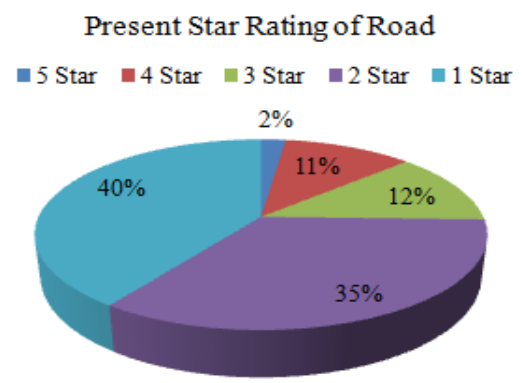

Figure 12. Present Star rating of study stretch

It is evident from figure 12 that about $78 \%$ of total sections are in either 1 or 2 star while $22 \%$ were in 3 or more star category.

\section{H. Star Rating after application of countrmeasures}

After incorporating the suggested countermeasures, again the improved road attributes data is fed into the iRAP model to get new star ratings for each section. Figure 13 enlists details of the revised star ratings which have been again rated from 1 to 5 stars.

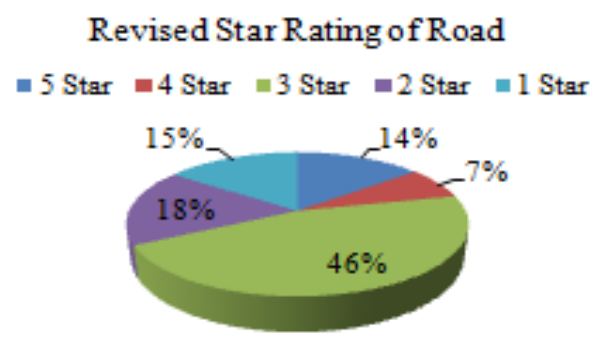

Figure 13. Revised Star Rating of Road

Its clearly evident from Figure 11 that now only $34 \%$ of total road sections lie in 1 or 2 star rating while $66 \%$ lieing in 3 or more star rating category. Its clarly a reversal of trend. This has happened only by just improving basic requirements at an economical rate. The improved ratings will ultimately help in reduction in acidents over the study stretch.

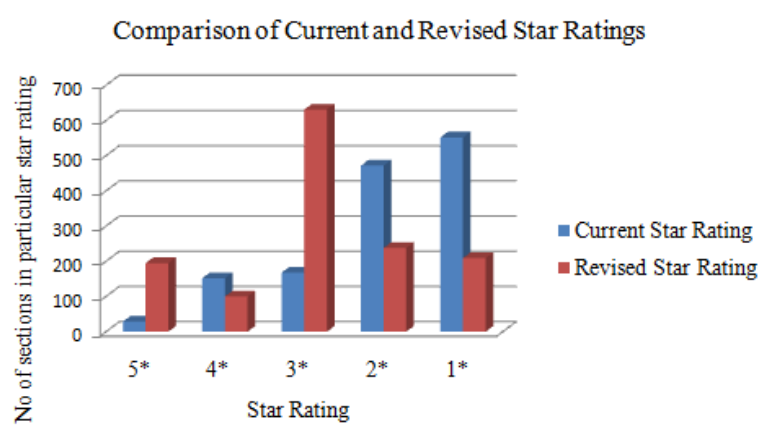

Figure 14. Compariosn between current and revised star ratings

\section{Conclusion}

This study generated star ratings for vehicular occupants for the study stretch of $137.3 \mathrm{~km}$ in accordance to iRAP methodology. It can be concluded from the study that, it is based on the principle that; at lower operating speed the relative risk of accidents involving fatalities and injuries is low as compared to higher operating speed. Shiradi Ghat section of road from Gundya to Sakleshpura is having majority of the road segments in 3 or more stars; despite the fact that it's full of sharp curves and poor road surface conditions. It is only possible because the Shiradi Ghat section is having lower operating speed $(40 \mathrm{kmph})$.

It has been explored from the study that the road section from B. C. Road to Gundya and Sakleshpura to Hassan bypass have a higher proportion of road in 1 star and 2 star category, while that of section of Shiradi ghat have higher proportion of road in 3 or more star category. This should effectively mean that the Shiradi Ghat section has less accident potential as compared to other two sections. But this fact is contradicted from accident data collected for this stretch henceforth, it warrants for further investigation for the application of iRAP in Indian conditions.

Furthermore, no consideration has been made to cater to the effect of pavement edge drop in iRAP methodology. It can contribute to about $2.5 \%$ of rural road accidents. The presence of pavement edge drop can itself induce run-off accidents according to the study made by Chandra [9]. The study stretch has deep pavement edge drops which is a safety concern.

Most of the details recorded pertaining to ground features is based on visual observation and judgement. Hence it lacks accuracy and may vary with the actual scenario. The ground features can be engineered and recorded accurately in a scientific way to get a more appropriate and reliable star rating of the road sections.

\section{Acknowledgment}

This work has been completely sponsored by TEQIP-II NITK, Surathkal. We acknowledge Dept. of Civil Engineering IGIT Sarang and NITK for their support.

\section{References}

[1] World Health Organizations (2013). "Global status report on road safety -Supporting a decade of action." Geneva 
Proc. of Fourth International Conference On Advances in Civil, Structural and Mechanical Engineering - ACSM 2016 Copyright (C) Institute of Research Engineers and Doctors, USA .All rights reserved.

ISBN: 978-1-63248-096-5 doi: 10.15224/ 978-1-63248-096-5-41

[2] Singh, P., and Vasudevan, V. (2013). "Development of panel models on traffic fatalities for regions with limited data." Procedia - Social and Behavioral Sciences, ELSEVIER, Agra, India, $1002-1010$.

[3] Ministry of Road Transport and Highways (2011),"Road Accident in India." New Delhi.

[4] Feedback Infrastructure Services Pvt. Ltd (2013). "Traffic surveys and analysis."Final feasibility cum preliminary project report for 4 lane of Hassan-Mangalore section of $\mathrm{NH}-48$ in the state of Karnataka, NHAI, 5.1-5.29.

[5] International Road Assessment Programme (2012). "iRAP India Four States Road Safety Report.” Australia.

[6] International Road Assessment Programme (2013). "iRAP Star Rating And Investment Plan Coding Manual.” London, England.

[7] International Road Assessment Programme (2011). "iRAP Road Attribute Risk Factors.” London, England.

[8] Karnataka Public Works Department (2012). "Road Traffic Survey Report.” Bangalore.

[9] Chandra R. (2004). "The Influence of pavement edge drops on highway safety." Missouri VITE Journal, Vol. 45(2), 6-10.

\section{About Author (s):}

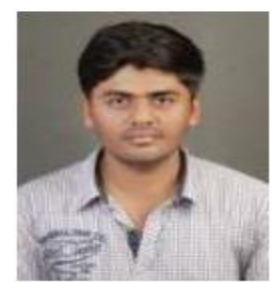

Sandeep Kumar Prusy,

M. Tech (HTTA),

Transportation System Engineering,

Dept. of Civil Engg, NITK, Surathkal,

Karnataka

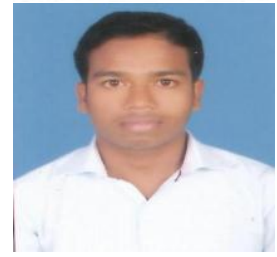

Soumya Ranjan Nayak

M.Tech

Transportation Engineering

Dept.Of Civil Engg, IGIT, Sarang

Odisha

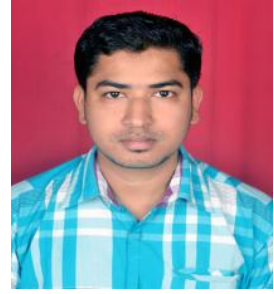

Rashmi Ranjan Barik

M.Tech

Transportation Engineering

Dept.Of Civil Engg, IGIT, Sarang

Odisha 